\title{
Deteksi Dini Gangguan Kognitif dan Depresi Pada Lansia
}

\author{
Resti Rahmadika Akbar*1, Dian Ayu Hamama Pitra², Mutiara Anissa ${ }^{3}$, Yuri Haiga4, Rahma Triyana ${ }^{5}$ \\ 1,2,3,4,5 Program Studi Kedokteran, Fakultas Kedokteran Universitas Baiturrahmah, Padang \\ *e-mail: restirahmadikaakbar@gmail.com
}

\begin{abstract}
Increasing the number of elderly people needs to be followed by programs that can maintain the quality of life of the elderly. The ratio of elderly dependence on the productive population is increasing. For that, we need a program so that physical and social changes in the elderly do not reduce the independence of the elderly. Physical changes in the form of cognitive disorders namely decreased brain function so that activities related to the ability of attention, concentration, calculation, decision making, reasoning, and abstract thinking. Social changes in the form of job loss, loneliness, risk of disease, can be a trigger for depressive disorders in the elderly. The purpose of this activity is for all parties to have a role in the early detection of cognitive disorders and depression as well as the elderly who have symptoms can be treated early.
\end{abstract}

Keywords: Elderly, Early Detection, Cognitive Disorders, Depression

\begin{abstract}
Abstrak
Peningkatan jumlah lansia perlu diikuti oleh program yang dapat menjaga kualitas hidup lansia. Rasio ketergantungan lansia terhadap penduduk produktif makin meningkat. Untuk itu perlu program agar perubahan fisik maupun social pada lansia tidak menurunkan kemandirian dari lansia. Perubahan fisik berupa gangguan kognitif yaitu penurunan fingsi otak sehingga kegiatan yang berhubungan dengan kemampuan atensi, konsentrasi, kalkulasi, mengambil keputusan, reasoning dan berpikir abstrak. Perubahan social berupa kehilangan pekerjaan, kesepian, risiko terkena penyakit, dapat menjadi pemicu gangguan depresi pada lansia. Tujuan kegiatan ini agar semua pihak memiliki peran dalam deteksi dini gangguan kognitif dan depresi serta lansia yang memiliki gejala dapat ditangani lebih awal.
\end{abstract}

Kata kunci: Lansia, Deteksi Dini, gangguan Kognitif, Depresi

\section{PENDAHULUAN}

Sistem kesehatan saat ini diatur dalam Jaminan Kesehatan Nasional (JKN). Pelayanan kesehatan bukan hanya mengenai pengobatan atau kuratif, tetapi harus mencakup holistik dan komprehensif. Pelayanan tersebut mencakup mengenai promotif, preventif, kuratif dan rehabilitatif. Pelayanan primer atau fasilitas kesehatan tingkat pertama berupaya memberikan pelayanan kesehatan bukannya kuratif, tetapi juga promotif dan preventif.( Susilo et al., 2018)

Jumlah lansia berdasarkan data pada tahun 2018 meningkat dua kali lipat sejak kurun waktu 50 tahun (1971-2018). Jumlah lansia sekitar 24,49 juta orang. Fenomena ini akan memberikan dampak yang berarti bila kehidupan lansia bisa mandiri, berkualitas dan tidak sebagai beban masyarakat.( Susilo et al., 2018))

Badan Statistik melampirkan data bahwa lansia hidup dengan penduduk produktif menunjukkan ketergantungan, rasio ketergantungan ini meningkat dari tahun sebelumnya menjadi $14.49 \%$. Artinya setiap 100 orang penduduk produktif harus menanggung 15 orang penduduk lansia. Selain family support, pelayanan kesehatan dan pelayanan lainnya yang berpihak pada lansia perlu dicanangkan, hal ini bukan hanya menjaid tugas pemerintah, tetapi juga peran dari masyarakat.( Syahrul, 2018; Susilo et al., 2018)

Dengan meningkatnya jumlah lansia, menjadi tantangan dalam menjaga kualitas hidupnya. Tantangan mengenai sosial ekonomi seperti pensiun dan ketidakmampuan untuk berperan di masyarakat serta ketergantungan pada anggota keluarga lain serta adanya penyakit penyerta.(Andesty et al., 2018) Masalah penuaan yang dialami berupa perubahan psikologis seperti short term memory, kecemasan dan depresi.(Andesty et al., 2018; Tanjung et al, 2019; Sundariyati, 2015) 
Klinik Peduli Sehat merupakan salah satu klinik, fasilitas kesehatan tingkat pertama yang melayani pelayanan kuratif serta promotif dan preventif. Pelayanan lebih utama dan dititikberatkan pada pelayanan pengobatan, sedangkan untuk promotif dan preventif dilakukan melalui penyuluhan dan pemasangan poster di klinik. Pelayanan deteksi dini seperti IVA atau Pap Smear sudah pernah dilakukan dengan bekerjasama dengan BPJS dan laboratorium. Sedangkan deteksi dini yang lain belum dilaksanakan secara optimal.

Deteksi dini khususnya untuk deteksi gangguan kognitif dan depresi pada lansia dilakukan secara berkala bertujuan untuk meningkatkan kualitas hidup lansia dan sebagai pedoman bagi keluarga untuk memberikan dukungan agar kehidupan mandiri pada lansia dapat diwujudkan.

\section{METODE}

Pelaksanaan kegiatan deteksi dini gangguan kognitif dan depresi pada lansia pada kegiatan penganbian ini dimulai dari:

\section{a. Survei lapangan}

Menggali permasalahan mitra, pada tahap ini ditemukan bahwa optimalisasi khusus pada lansia untuk kegeiatan preventif dan promotive belum dilakukan. Survei awal ini bertujuan juga untuk melihat berapa banyak jumlah pasien lansia, dan bentuk promotive dan preventif yang telah dijalankan pada lansia. Kegiatan yang bersifat promotive dan preventif berupa penyuluhan dilakukan sesuai dengan tema yang sudah ada.

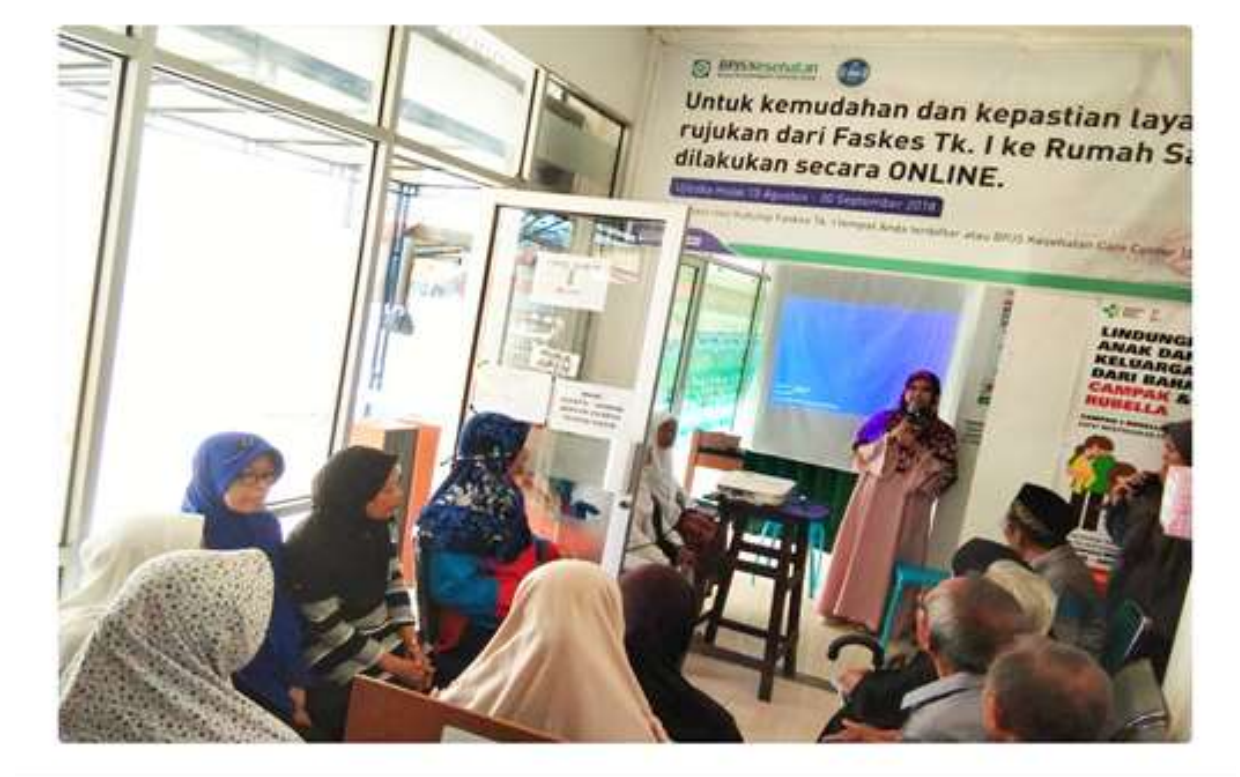

Gambar 1. Pembukaan acara penyuluhan

\section{b. Sesi Penyuluhan}

Memberikan penyuluhan mengenai materi gangguan kognitif dan depresi pada lansia yang disampaikan oleh spesialis neurologi dan kejiwaan. Setelah penyuluhan kemudian dilanjutkan dengan diskusi berupa tanya jawab dengan pakar. 


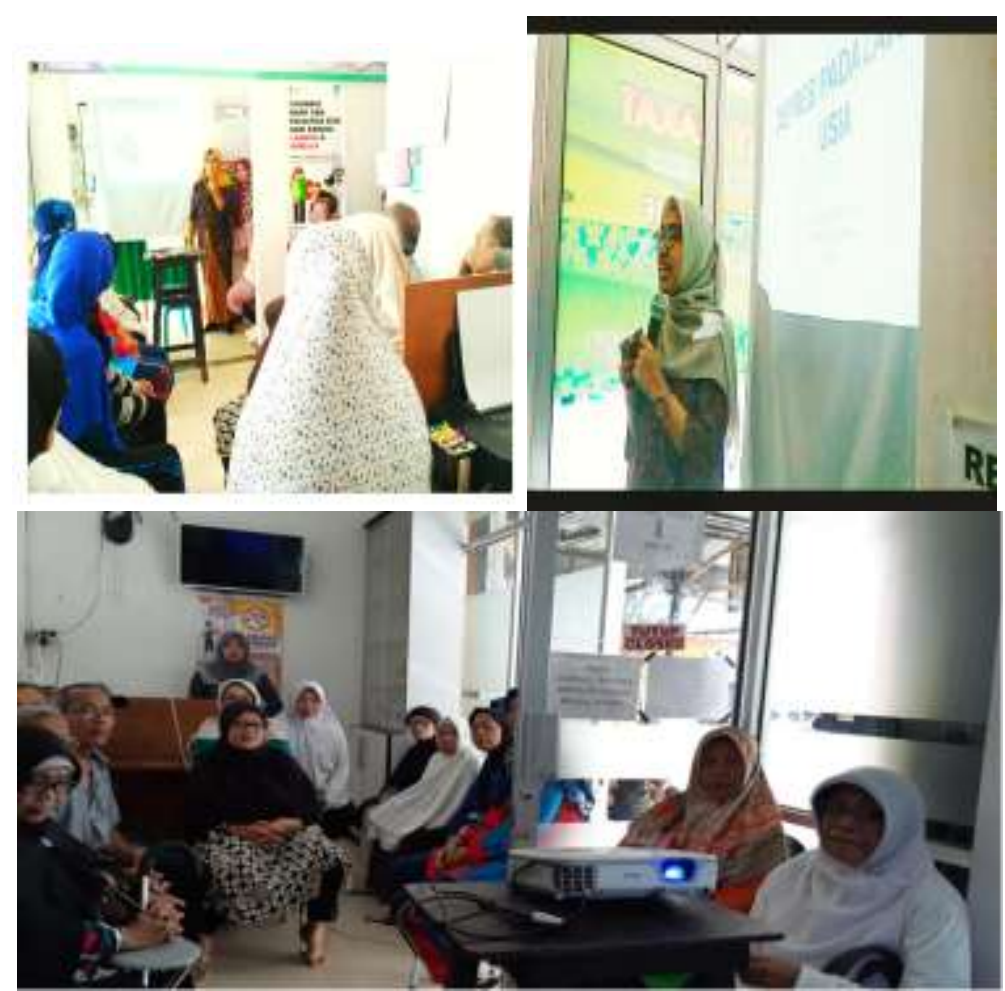

Gambar 2 Penyuluhan Gangguan Kognitif dan gangguan Depresi

\section{c. Sesi Pencatatan}

Dengan menggunakan beberapa formulir dicatat data melalui wawancara yang dilakukan oleh beberapa orang dokter. Formulir penilaiandeteksi dini depresi menggunakan Geriaric Depression Scale (GDS 15), dan deteksi dini gangguan kognitif menggunakan Motreal Cognitive Assessment versi Indonesia (MOCA-Ina).

Lansia yang hadir di klinik saat melakukan pengabdian akan dilakukan pemeriksaan oleh dokter dan dilakukan rekap data sehingga akan dihasilkan kesimpulan gejala depresi ataupun gangguan kognitif.

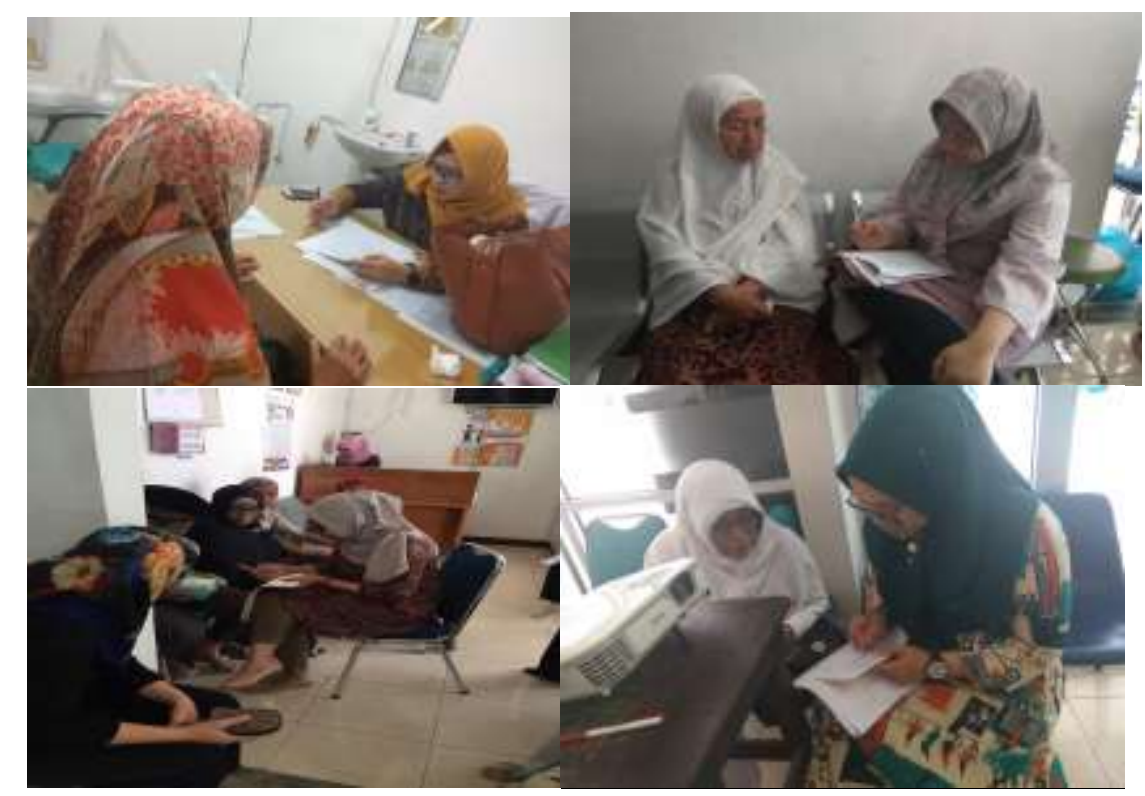

Gambar 3 pencatatatan dan penilaian deteksi dini 
d. Sesi evaluasi

Pada lansia tersebut dijelaskan hasil mengenai deteksi dini tersebut, bila lansia didampingi oleh keluarga, maka penjelasan juga disampaikan pada keluarga. Pada sesi ini, sesuai dengan tujuan yaitu melakukan deteksi dini gangguan kognitif dan depresi pada lansia. Hasil dari penyuluhan didapatkan lansia muda sebanyak 60\% dan 40\% lansia madya. Dari semua peserta yang hadir umumnya menunjukkan kemandirian.

\section{HASIL DAN PEMBAHASAN}

Kegiatan ini dihadiri oleh dokter klinik, perawat, lansia yang berada di sekitar klinik dan pasien klinik. Lansia yang akan menerima penyuluhan dan

Luaran yang dihasilkan dari rangkaian pengabdian ini berupa:

1. Tenaga medis dan paramedik di klinik memiliki kesempatan untuk melaksanakan deteksi dini.

2. Tersedianya instrument untuk pelaksanaan skirining/deteksi dini berikutnya.

3. Peserta pengabdian yaitu lansia, mengenali gejala-gejala depresi serta gangguan kognitif, sehingga bisa ditangani lebih awal.

Dengan melibatkan komponen klinik dalam melakukan deteksi dini, diharapkan metode ini dapat dilakukan kembali untuk program promotive dan prevenstif di layanan kesehatan tingkat pertama. Pelayanan yang komprehensif tidak hanya mengenai pengobatan atau kuratif, tetapi juga mencakup pelayanan pada promotive, preventif. Kuratif dan rehabilitatif.

Hasil pemeriksaan gangguan kognitif menggunakan Montreal Cognitive Assessment versi Indonesia (MoCA-Ina).

Tabel 1. Hasil pemeriksaan fungsi kognitif

\begin{tabular}{lll}
\hline Fungsi kognitif & F & $\%$ \\
\hline Normal & 2 & 8 \\
Mild kognitif & 19 & 76 \\
Demensia & 4 & 16 \\
\hline
\end{tabular}

Dari hasil deteksi dini didapatkan hasil 76\% mengalami gangguan kognitif ringan (mild kognitif), sedangkan 16\% telah menunjukkan gejala demensia. Seiring bertambahnya usia, penuaan merupakan hal yang tidak dapat dihindari. Perubahan bukan hanya dari aspek sosial tetapi juga fisik dan kejiwaan. Perubahan tersebut juga memberikan efek pada kemandirian lansia dalam melakukan aktivitas sehari-hari. Perubahan berupa gangguan kognitif yang mengarah pada demensia menyebabkan penurunan fungsi otak sehingga kegiatan yang berhubungan dengan kemampuan atensi, konsentrasi, kalkulasi, mengambil keputusan, reasoning dan berpikir abstrak.(Andesty et al., 2018; Djajasaputra, 2019; Susilo et al,2018; Rasyid IA et al, 2017; Sari et al., 2018)

Hasil pemeriksaan depresi menggunakan kuesioner Geriatic Depression Scale (GDS) didapatkan:

Tabel 2. Pemeriksaan Depresi pada lansia

\begin{tabular}{lll}
\hline Skala & $\mathrm{F}$ & $\%$ \\
\hline Normal & 21 & 84 \\
Kemungkinan depresi & 4 & 16 \\
Depresi & 0 & 0 \\
\hline
\end{tabular}


Dari hasil pemeriksaan didapatkan peserta yang mengalami kemungkinan depresi yaitu 16\%. Depresi pada lansia disebabkan oleh berbagai faktor salah satunya penyakit degenerative yang dialami, dukungan keluarga dan masyarakat terhadap lansia, dan kemandirian lansia dari segi fisik, sosial, dan finansial. (Syamsuddin, 2010; Wikananda, 2017)

Peningkatan jumlah lansia dan ketergantungan lansia pada penduduk produktif sesuai dengan data di badan statistik, dapat ditindaklanjuti dengan meningkatkan peran lansia agar dapat mandiri secara pribadi. Kehilangan pekerjaan, kehilangan teman, risiko terkena penyakit, terisolasi dari lingkungan dan bahkan penyakit yang diderita saat ini dapat meningkatkan risiko depresi. Pengenalan gejala depresi ini perlu dikenali bukan hanya oleh lansia tetapi oleh keluarga.(Susilo et al, 2018), (Wikananda, 2017),(Nur Rohmah, 2012)

\section{KESIMPULAN}

Berdasarkan hasil pelaksanaan kegiatan yang telah dilakukan, dapat ditarik kesimpulan sebagai berikut:

1. Kegiatan skrining dapat menjadi kegiatan berkala yang dapat dilaksanakan di fasilitas kesehatan tingkat pertama

2. Penyadaran tenaga medis dan paramedic untuk meningkatkan peran dengan memajukan usaha promotif dan preventif pada lansia

3. Penyadaran bahwa jumlah lansia yang meningkat perlu diimbangi dengan program dari pemerintah dan peran serta aktif seluruh masyarakat.

Oleh karena itu para lansia perlu mendapat perhatian dan dukungan dari lingkungan dan keluarga agar dapat mengatasi perubahan yang terjadi, selain perubahan keadaan fisik dan keadaan mental yang makin rentan. Layanan BPJS Kesehatan tentunya diharapkan bisa membantu masyarakat.

\section{DAFTAR PUSTAKA}

Andesty, D., Syahrul, F., Epidemiologi, D., Masyarakat, F. K., \& Airlangga, U. (2018). Hubungan Interaksi Sosial Dengan Kualitas Hidup Lansia Di Unit Pelayanan Terpadu ( Uptd ) Griya Werdha Kota Surabaya Tahun 2017 Pendahuluan Dampak dari kemajuan ilmu pengetahuan dan teknologi terutama di bidang kesehatan, berhasil untuk menurunkan angka. The Indonesian Journal of Public Health, 13(December), 169-180. https://doi.org/10.20473/ijph.vl13il.2018.169-180

Djajasaputra, A. D. R., \& Halim, M. S. (2019). Fungsi Kognitif Lansia yang Beraktivitas Kognitif

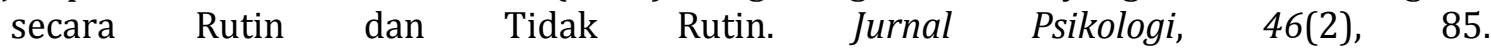
https://doi.org/10.22146/jpsi.33192

Dwi Susilo, Ida Eridawaty Harahap, R. S. (n.d.). Statistik Penduduk Lanjut Usia 2018.

Tanjung et al (2019). Gambaran Gangguan Kognitif Dan Fungsional (Iadl)Padalansia Di Kelurahan Kramas,Kecamatan Tembalang, Kota Semarang. Jurnal Kesehatan Masyarakat (eJournal), 7(1), 168-175.

Harry Sundariyati, I. G. A., Ratep, N., \& Westa, W. (2015). Gambaran faktor-faktor yang mempengaruhi status kognitif pada lansia di wilayah kerja puskesmas kubu II, JanuariFebruari 2014. E-Jurnal Medika Udayana; Vol 4 No 1 (2015):E-Jurnal Medika Udayana. Retrieved from https://ojs.unud.ac.id/index.php/eum/article/view/12634

Nur Rohmah, A. I. (2012). Kualitas Hidup Lanjut Usia. Jurnal Keperawatan, 3(2), 120-132.

Rasyid IA, Syafrita Y, \& Sastri S. (2017). Hubungan faktor resiko dengan fungsi kognitif pada lanjut usia kecamatan padang panjang timur kota padang panjang. Hubungan Faktor Resiko Dengan Fungsi Kognitif Pada Lanjut Usia Kecamatan Padang Panjang Timur Kota Padang 
Panjang, 6(1), 49-54.

Sari, D. M. P., Lestari, C. Y. D., Putra, E. C., \& Nashori, F. (2018). Kualitas Hidup Lansia Ditinjau Dari Sabar Dan Dukungan Sosial. Jurnal Ilmiah Psikologi Terapan, 6(2), 131. https://doi.org/10.22219/jipt.v6i2.5341

Syamsuddin. (2010). Depresi Pada Lansia. Depresi Pada Lansia, 1-19.

Wikananda, G. (2017). Hubungan Kualitas Hidup dan Faktor Resiko pada Usia Lanjut di Wilayah Kerja Puskesmas Tampaksiring 1 Kabupaten Gianyar Bali 2015. Intisari Sains Medis, 8(1), 1-12. https://doi.org/10.15562/ism.v8i1.112 